\title{
Achieving Competence-Based Curriculum in Engineering Education in Spain
}

\author{
An education program, now in development, aims to ease cross-border \\ transfers for students seeking further study, and to expand the \\ labor market for graduates, teachers and administrative staff.
}

\author{
By Mónica Edwards, Luis Manuel Sánchez-Ruiz, and Carlos Sánchez-Díaz
}

ABSTRACT | The fact of placing competences and outcomes learning at the heart of the academic activity means overhauling the curricular architecture of higher education in Europe. Some universities have undergone important transformations moving toward a competence-based learning environment, while others maintain traditional curriculum packaged formats. In the realm of the European Higher Education Area, this paper examines the use of competence-based initiatives in curricular development for engineering degrees with special focus to the Spanish case. Although the concept of competence and competence-based learning has a long history in education and training research, these terms are still very diffuse and demand a clear conceptualization. In the first part of this paper, we provide a conceptual overview and a critical reflection of competences as implemented in a wide range of settings, including its origins, key concepts, and definitions. Next, we discuss the purposes, principles, pitfalls, and processes that enable defining a map of competences within engineering education. Lastly, we present a pilot project involving curriculum development and faculty enhancement within a competence-based learning initiative in Electronic Engineering.

Manuscript received December 5, 2008. Current version published September 16, 2009. This work was supported in part by the Program of European Convergence (Universidad Politécnica de Valencia) and developed within the Project of Adaptation to the European Higher Education in the School of Design Engineering. M. Edwards is with INGENIO (CSIC-UPV), Universidad Politécnica de Valencia, Valencia, Spain (e-mail: moed@ingenio.upv.es).

L. M. Sánchez-Ruiz is with the Universidad Politécnica de Valencia, Instituto Universitario de Matemática Pura y Aplicada, Departamento de Matemática Aplicada Valencia, Spain (e-mail: Imsr@mat.upv.es).

C. Sánchez-Díaz is with the Instituto de Ingeniería Energética, ETSID-Departamento de Ingeniería Electrónica, Universidad Politécnica de Valencia, Valencia, Spain (e-mail: csanched@eln.upv.es).

Digital Object Identifier: 10.1109/JPROC.2009.2026064
KEYWORDS | Competences; curricular development; engineering education; European Higher Education Area (EHEA); learning

\section{INTRODUCTION}

Nowadays the whole engineering community is immersed in a vigorous debate trying to fix the competences needed for current and future engineering practice [1]-[3]. Some trends have the potential to change the practice of engineering and engineering education significantly: the general technological advances and pervasive use of information technology; the modification of value-added chains; the vast array of new materials and processes that broaden engineers design space; the increasing number and complexity of economical, political and ethical constraints (e.g., cost, safety, sustainability); the need for teamwork; and fast-paced change, calling for lifelong learning [2], [3].

In the movement to the European Higher Education Area (EHEA), competences and learning outcomes are playing a central role and are considered to be a keystone when dealing with two problems that the current engineering education system has to face: the fast technological change in the production and management of knowledge and the gap between education and job market requirements [4]-[6]. On the other hand, some studies show different patterns between acquired and required competences in the Mediterranean countries compared with the rest of European countries [5]-[7].

Formation based on competences is viewed as one of the pillars to advance in the EHEA process despite the fact that many important issues about its conceptualization and applicability remain unclear [8]-[10]. In this paper, we provide a critical reflection of the competence-based 
initiatives in engineering education. In Sections II and III, we present an overview of the importance, the historical background, and the meaning of competences. In Section IV, we focus on the Spanish particular situation but our methods and conclusions may be extrapolated to other countries. In Section V, we explain the experience in competence mapping in electronic engineering at the School of Design Engineering, Polytechnic University of Valencia.

\section{AN OVERVIEW ON COMPETENCES}

\section{A. Importance}

Why this renewed interest and relevance in implementing competence-based initiatives in colleges and universities? This question may receive different answers depending on the perspective from which it is perceived. First, the competence-based terminology might be considered more adequate for consultation and dialogue with many stakeholders as employers, graduated and other social agents. It can contribute both to the necessary reflection for the development of new degrees and to update the existing ones, thus reducing the effects of the mismatch between acquired and required level of competences in the labor market [5]-[11].

Secondly, competences empower tendencies such as vocational education and training and lifelong learning (LLL). In today's society, individuals are required to be flexible in terms of being proactive and adaptable (LLL) as well as in terms of mobility (employability) [8]-[13].

Thirdly, competences are a nuclear concept in the new teaching/learning paradigm, where approaches centered on the learner are increasingly important. It summarizes academic and professional profiles, defines new objectives in the learning process, enhances learning environments, and shifts the concept of learning as accumulation of knowledge to learning as a permanent attitude towards knowledge acquisition. In fact, competence-based education is considered the leading paradigm for innovation since it emphasizes the integrated nature of what students need to learn to face not only the labor market but also life in general [13], [14].

From the curricular perspective, specific articulations of competences inform and guide the basis of subsequent assessments. In this way, competences provide directions to design learning experiences and assignments that help students gaining practice in their use and application in different contexts [15], [16]. This emphasis from inputoutput in the learning process is reflected in the assessment of student performance, moving from knowledge as the dominant (when not the single) reference to include a variety of approaches to assessment (portfolio, tutorial work, course work; peer, co- and self-assessment; etc.). Current competence-based education gathers features of several other educative innovations, such as self- regulated learning, project-based learning (PBL), coach learning, etc.

Competences and learning outcomes allow flexibility and autonomy in the construction of curricula and at the same time are the basis to formulate commonly understood level indicators. From this perspective and within the process of building up an EHEA, competence-based learning contributes to the introduction of the European Credit Transfer System (ECTS), facilitating the comparability and compatibility of educative systems [11]. At the 2003 Berlin meeting, the Bologna Working Group on Qualifications Frameworks (2004) encouraged Member States "to elaborate a framework of comparable and compatible qualifications for their higher education systems, which should seek to describe qualifications in terms of workload, level, learning outcomes, competences and profile." At present, there are four strata of qualification frameworks in different stages of development in the EHEA. The most general that has been agreed to and promulgated is the transnational Framework for Qualifications of the EHEA, gathering the "Dublin descriptors" and setting out definitions and levels of competences for a bachelor's degree, a master's degree, and a doctoral degree [12].

\section{B. Historical Background}

There are a variety of perspectives about the origin of competences, with backgrounds in diverse areas such as linguistics, cognitive psychology, business organization, management development, and education [14]-[18], thus being able to find that the terms competence and competency are used in various ways in the literature [10]-[19].

Although these concepts are commonly used in the educative area in some European countries (United Kingdom, Denmark, Finland, France, among others) there is an increasing criticism about the ambiguity of its use and the lack of a theoretical frame supporting it [8]-[26]. In this way, Weinert affirms that there is no basis for a theoretically grounded definition or classification from the seemingly endless inventory of the ways in which the term competency is used, which range from scientific discussion to the political discourse [18].

A very first question that arises is: Should we use the term competence or competency? In a 1995 article entitled "Demystifying Competence," Armstrong asked, "What does competence mean? It is all very confusing. Every definition is different. We hear about competences and competencies and are told that competence is quite different from competency and the two terms should never be confused" [19]-[44].

Educators usually define competences as indicators of profits, knowledge, and capacities, while, on the other hand, employers and economists associate them with performance, productivity, efficiency, and professionalism [20].

The terms "competencies," "competence," and "competent" refer to a state or quality of being able and fit. Some English dictionaries describe the word competence as 
the quality or state of being suitable, sufficient, or fit and, for the word "competency," refer readers to "competence." However, most of them make the following distinction: "competence" means demonstrating the knowledge, skills, experience, and attributes necessary to carry out a defined function effectively and "competency" alludes to the description of the knowledge, skills, experience, and attributes necessary to carry out a defined function effectively. In other words: competency seems to be a description of behavior, and competence a description of work tasks or job outputs. We embrace distinguishing these two concepts in such a way that competence and competences refer to broad capacities; in contrast, competency (plural competencies) is a narrower, more atomistic concept used to label particular abilities.

It is not strange that competences mean different things to different people since, by means of a short bibliographical insight, we have found three historical approaches in its use: in the psychological field, in the business/human resources field, and in the educational field. From these, the last two, competence organizational-training and competence-based teacher training, seem to be the principal approaches and were developed in the United States, having a wide and similar development in United Kingdom and Australia [19]-[22]. In fact, the origin and development of the competence movement specifically within the educational field is not clear. During the 1960s and 1970s, the "competency movement" was characterized by detailed analysis of professional tasks and job tasks were dissected into long lists of behavioral elements. Thus, competencebased education became primarily associated with behaviorism and modular teaching in skill-based instruction [23].

Grant et al. [24, p. 6] in 1979 defined competence-based education as "a form of education that derives a curriculum from an analysis of a prospective or actual role in modern society and that attempts to certify student progress on the basis of demonstrated performance in some or all aspects of that role," concluding that competence is a broad term, and that the programs based on competences can be very diverse with respect to their theoretical orientation, scope, intentions, and scientific focus. These scopes of competences, primarily centered in programmed instruction models, went progressively enriched with contributions of the cognitive learning theories [10].

In the 1990s, pedagogical innovation, new methodologies, assessment learning, and quality of education matured and got a critical position in competence-based education. These programs have the drawback of a rigid mapping and an untouchable starting point for the definition of occupational competences, leading to routine job descriptions in which the proactive and reflective worker is left out [25]. Competence-based training was considered appropriate within a Taylorist management environment but seems to be inadequate for today's society, where the industrial base is supplanted by the "knowledge economy." The new scenario of the highly skilled work- place requires a more holistic approach, centered in flexibility and problem-solving abilities, with a different and more active role of the worker [26]. Cross and Israelit affirm that "today's knowledge worker is valued precisely for his or her ability to contribute with unique knowledge, skills and perspectives - a highly subjective process that, at best, can only be developed when technologies form the heart of what most organizations are calling knowledge management" [27].

In addition, competences in education may be viewed from theoretical, operational, and holistic perspectives. From a theoretical perspective, competence is defined as a cognitive structure that facilitates a specific behavior. From an operational perspective, competences seem to cover a broad range of higher order skills and behaviors that represent the ability to cope with complex, unpredictable situations; this operational definition includes knowledge, skills, attitudes, metacognition, and strategic thinking, which presupposes conscious and intentional decision-making [10]-[26].

A holistic vision (global approach) of the competence does appear when constructivism reigns and the context acquires special relevance. According to Stoof et al., it is necessary to determine the viability of the competences for which they propose the use of three variables as prerequisites: people, goal, and context [15].

Sullivan emphasizes framing competencies (and outcomes) around three apprenticeships - head (intellectual development), hand (skill development) and heart (modes of thinking, habits of mind) [28].

Another problem arises when educators focus on the method of how to teach competences rather than what competences our students should learn. At what dimension and level? All these considerations determine the existence of great difficulties for the curriculum design.

\section{APPROACH TO COMPETENCE MEANING WITHIN EHEA}

From the previous section, we deduce that competence is a polysemic word and has been defined and used in a variety of areas during the last four decades [29]. In the context of the educational field, this term has frequently been used to mean student outcome, learning outcome, objective, skill, or ability, among others [26]-[30].

Despite some attempts (e.g., IEEE Learning Technology Standards Committee, ABET, Tuning and Deseco Projects, etc.), there are still different definitions and methodologies associated with competences [11]-[32]. So we find, for example, that social competences (that tend to be intangible) are frequently understood in a different way from technical ones (that tend to be more tangible). On the other hand, the word's conceptual meaning also varies throughout different countries and cultures. It is not clear if competence refers to what people are able to do, should be able to do, must do, or will really do to achieve 
professional success. This confusion often reflects inconsistent usage of terms as much as different cultural traditions or epistemological assumptions [30]. A tacit understanding of this "fuzzy concept" has been overtaken by the need to define it precisely and to establish a minimum consensus, but the practical has become shrouded in theoretical confusion, and the apparently simple has become complicated [33], [34].

Mansfield contrasts three different usages of competence: outcomes (vocational standards describing what people need to be able to do in employment); tasks that people do (describing what currently happens); and personal traits or characteristics (describing what people are like) [35]. In a recent report, the Centre for European Research on Employment and Human Resources has presented a prototype typology of knowledge, skills, and competence. In the words of Winterton et al., while a person may have the skills or knowledge (competency) to perform a task, this does not mean that he or she will have the desire (attitude) to do so correctly (performance). In other words, competences give a person the ability to perform, while attitudes give a person the desire to perform [30].

Employers demand graduates who are able to operate in complex environments, e.g., environments characterized by ill-defined problems, contradictory information, informal collaboration, and abstract, dynamic, and highly integrated processes. The concept of competence is strongly associated with the ability to master such complex situations, and for this reason, it is assumed that "competence" transcends the levels of knowledge and skills to explain how knowledge and skills are applied in an effective way [10]. Competence includes high-order abilities related with being able to learn, adapt, anticipate, and create rather than being able to demonstrate that one has the ability to do [36].

In the "Tuning Educational Structures in Europe" project coordinated by the University of Deusto in Bilbao, Spain, and the University of Groningen, The Netherlands, competence is defined as "a dynamic combination of attributes - with respect to the knowledge and its application, to the attitudes and responsibilities that describe the results of learning a determined program, or how the students will be able to develop at the end of the educative process" [11]. The Tuning project makes a distinction between learning outcomes and competences to distinguish the different roles of the most relevant players: academic staff and students/learners. Desired outcomes of a learning process are formulated by the academic staff, preferably with the input of student representatives, on the basis of input from internal and external stakeholders (employers, graduated, etc.), while competences are obtained or developed during the process of learning by the student/learner. Both competences and learning outcomes can be identified and related to whole programs of study (first or second cycle) and for individual units of study (modules), specifying the requirements for award of credit.

\section{COMPETENCE-BASED EDUCATION INITIATIVES IN SPAIN}

In contrast with a long experience and background in other countries, competence-based initiatives in Spain are at the early stages of development.

The most commonly assumed scopes of initiatives have been taken following the Tuning project, which provides a methodology that produces "reference points" for faculty developing statements of learning outcomes, levels of learning, and desired competences in the disciplines so that those statements are clear and easily comparable. It seeks to assist institutions and faculty in describing cycle degree programs at the level of subject areas and to establish a "common language" that expresses what a curriculum design at a specific institution aims to do but does not prescribe the means of doing it; thus the Tuning notion focuses on "convergence."

For this project, a review of more than 20 studies in the field of generic skills and competences was carried out, identifying a list of 85 different competences. They were classified into two types: 1) generic or transversal competences, which in principle are subject independent, and 2) subject-specific competences.

The generic competences identify shared attributes that could be general to any degree, such as the capacity to learn, decision-making, communication abilities, project design, teamwork and management skills, etc., which are common to all or most degrees. Specific competences play a crucial role to prepare students for the profession or the type of jobs for their educational program. The generic competences were in turn well categorized in the Tuning project as instrumental, interpersonal, and systemic.

- Instrumental competences include:

- cognitive abilities; capacity to understand and manipulate ideas and thoughts;

- methodological capacities to manipulate the environment by organising time and strategies of learning, making decisions, or solving problems;

- technological and management skills related to use of digital devices, computing, and information systems;

- linguistic skills such as oral and written communication or knowledge of a second language.

- Interpersonal competences include:

- individual abilities concerning the capacity to express one's own feelings;

- social skills such as interpersonal communication, teamwork, or an active attitude in order to get social and ethical commitment; these competences tend to favor processes of social interaction and cooperation.

- Systemic competences include those skills and abilities concerning whole systems. They suppose a 
combination of understanding, sensibility, and knowledge that enables one to see how the parts of a whole relate and come together. These capacities include the ability to make improvements and design new systems. Systemic competences require the prior acquisition of instrumental and interpersonal competences.

In 2002, the Spanish Ministry of Education founded the National Agency for Quality Assessment and Accreditation, whose first task was to encourage universities to implement conversion projects for syllabus and degrees conforming with EHEA. For the elaboration of these projects (called White Books), it has been considered a high priority to approximate the required competences from the perspective of the different stakeholders: employers, academic, graduates, students, and other social agents. The official document provided by the Ministry of Education, "The Integration of the Spanish Higher Education System in the European Higher Education Area," affirms that the official degrees will have to provide a university formation in which the generic (basic) competences related to the integral formation of the people are harmonically integrated with specific competences that make possible a professional profile and enable the graduates to get integrated into the job market [37].

\section{COMPETENCES MAPPING IN ENGINEERING CURRICULUM}

\section{A. The Context of the School of Design Engineering}

Over the last several decades, Spain has undergone a profound social and economic change that has greatly affected its higher education system and whose structural reform has modernized universities and brought democracy to them. Despite these facts, the current academic culture, including the formative processes in which teachers and students are involved, is not meeting the needs of the new situation.

Within this scenario, the School of Design Engineering (ETSID) at Polytechnic University of Valencia, with approximately 3500 students, 310 academic staff, and 30 administrative staff, has been involved, for many years, in a deep process of global quality assessment and improvement. This process has always kept three major fundamental priorities in mind: a) educational innovation; b) close relationship with the socioeconomic and industrial environment; and c) international relations. Hence ETSID has some strong pillars that facilitate the European convergence and the Bologna process [40].

\section{B. Experience of Adaptation to EHEA at ETSID}

During the 2003-2004 and 2005-2006 academic years, several projects in engineering education to adapt the EHEA at ETSID were implemented, involving curric- ulum development and faculty enhancement. The aim of these projects was:

a) to establish a curricular structure for competencesbased and well-defined professional profiles,

b) to adapt the formative programs according to the ECTS recommendations and requirements,

c) to develop curriculum materials to meet key competences and learning objectives, increasing the use of active methodologies with continuous and formative assessment,

d) to elaborate information documents about the study programs and the results of the students in normalized format (information package);

e) to manage an action agenda in the gradual implementation of the changes (surveys to institutions, employers, students, and administrative staff). In Fig. 1, we show the flow of this process.

The project development paid special attention to staff participation, since previous studies had shown the lack of success of innovation projects due to the failure of teachers to implement the intentions of the developers [38]. In order to reduce the chances this might happen at ETSID, leading administrators presented the project to the whole center (academics, students, administrative and other personnel), specifying the different phases and organizational structure, discussing the strategies, planning the tasks, and encouraging them to conceptualize and suggest changes as appropriate.

A diagnosis of the situation was simultaneously made with the initial actions in the projects undertaken. Surveys to professors and students were applied to evaluate their degree of information on subjects concerning European convergence and ECTS [39], [40]. Table 1 and Fig. 2 show a list of the obstacles and difficulties in decreasing order of importance for the adaptation to the ECTS indicated by the 37 teachers that answered the survey (out of 69 to whom it was sent) [40].

In the student samples, the ignorance of EHEA issues was very high, as shown in Fig. 3, which represents the number of affirmative answers to the question: "Do you know the meaning of the expression European Higher Education Area?"

Hence only in the chemical and design engineering cases did more than half- $63.2 \%$ and $51.6 \%$, respectively - of students knew the meaning of EHEA.

The results were worse when the students answered the question, "Do you know the European Credit Transfer System?" We may observe in Fig. 4 that only $37.3 \%$ of design engineering students responded affirmatively to this question, $14.5 \%$ in the electronics case, $8.4 \%$ in mechanics, and $7.6 \%$ in electrical engineering. It is surprising that even students that know about EHEA do not know about ECTS [40].

Having in mind these difficulties, we provided enough time to enable participants to fully reflect upon potential profiles and reach consensus. A poster competition was organized to provide an institutional slogan, as well as 


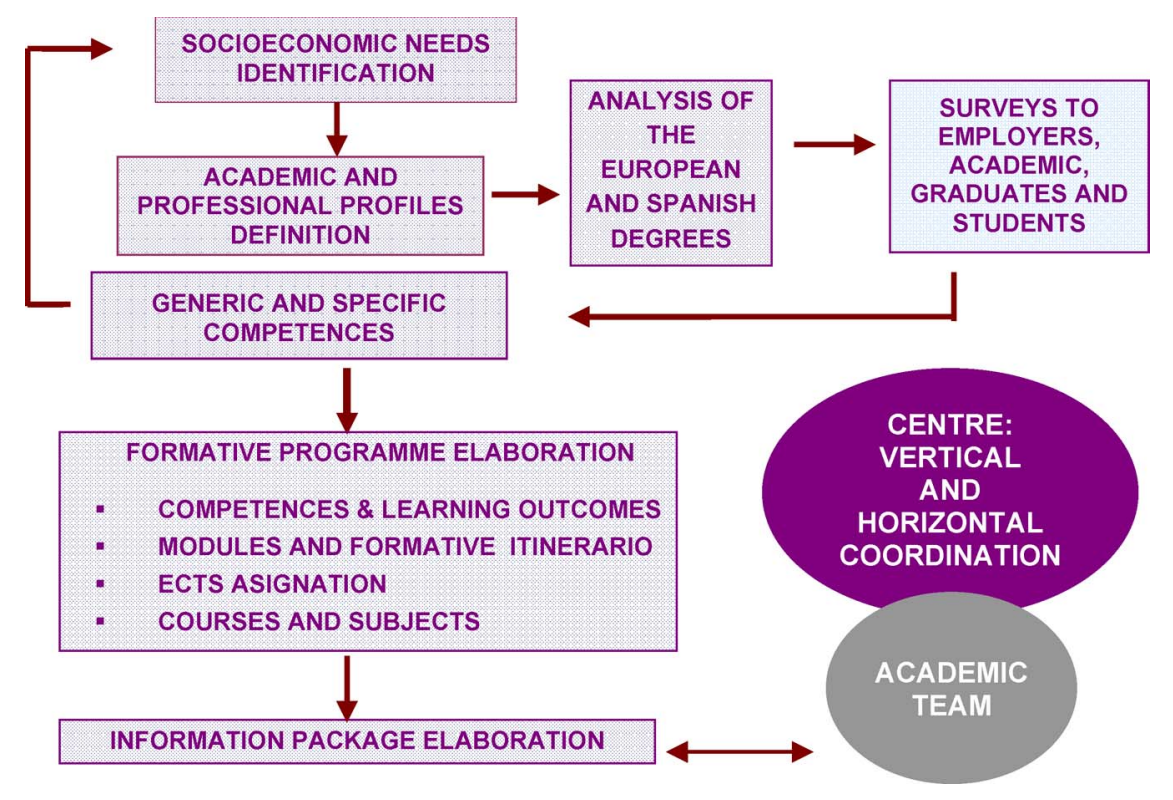

Fig. 1. Scheme of design degree in the project adaptation to EHEA.

awareness weeks specifically oriented to the students. The winning posters were exhibited for a month, along with explanatory booklets with EHEA information.

With the aim to improve the participation and involvement of the academic staff, formal workshops were organized allowing staff to experiment with new ideas and providing informed advice from experts about how they might strengthen their definitions of competences. These workshops were usually offered on a regular, consistent basis with follow-up discussions and meetings rather than as a single event [39].

Table 1 Teachers' Concern About Obstacles and Difficulties for Adaptation to ECTS $(N=37)$

\footnotetext{
a Large classes, with an excessive number of students.

b Determination of student workload.

c Active methodologies application.

d Change in assessment methods.

e Definition and application of competences.

f Reorganization of physical and human resources.

g Determination of curriculum goals.

h Need of new spaces resources (TIC, seminar rooms, etc.).

I Contents reorganization.

j Poor information about the Bologna process.
}

Simultaneously, we reviewed multiple sources of information about competences, with the Tuning approaches being the most relevant along with the ABET EC-2000 criteria, results of the CHEERS survey, and IEEE Learning Technology Standards [5]-[41]. Therefore, competences were established, understood, and accepted. At this point, faculty and staff began to reevaluate the curriculum and moved toward identifying and articulating relevant and current competences. Thus we started with up-down method criteria and tried to reach a first approach to a core set of competences with bottom-up input.

\section{Competences Mapping}

We define competence mapping as the process of identifying key competences for a particular degree within an institution. The key process of this competence mapping method has been a gap analysis between the most

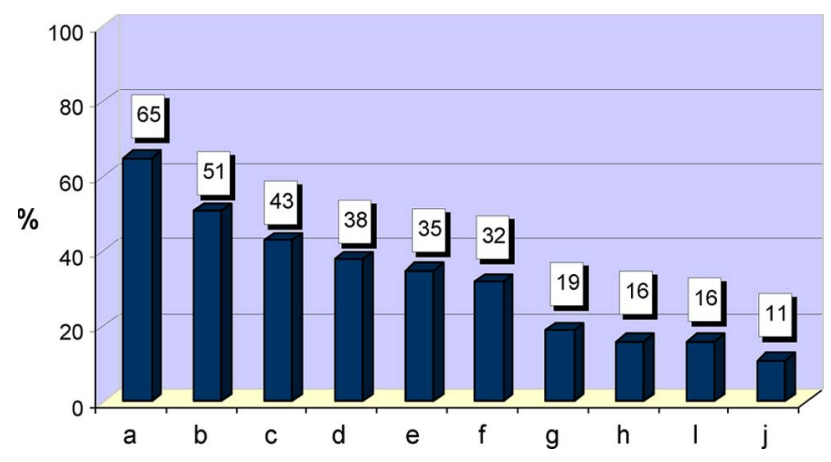

Fig. 2. Percentage of concerns relative to the items of Table 1. 


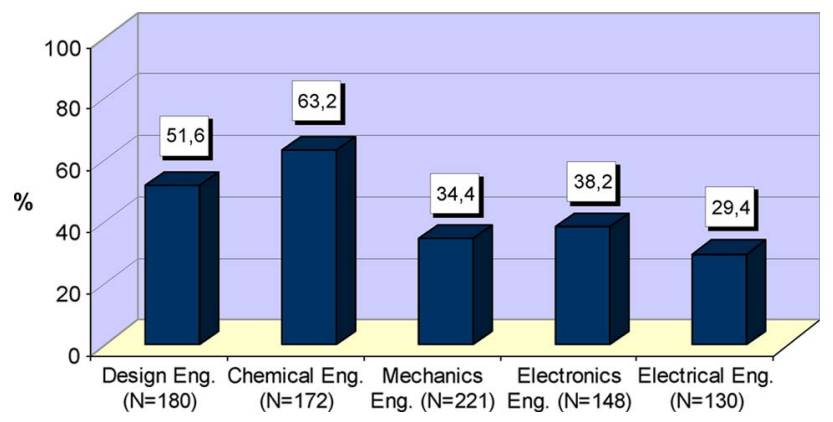

Fig. 3. Students' knowledge on the meaning of EHEA $(\mathrm{N}=180$ design engineering; $N=172$ chemical engineering; $N=221$ mechanical engineering; $N=148$ electronics engineering; $N=130$, electrical engineering).

required competences and the highest deficits in the majority of European countries, particularly in Spain [5]-[11]. With the relevant competences preidentified in the pilot projects, we elaborated a list and asked faculty and the different stakeholders to identify the most important areas within the curriculum. The results that we obtained in a set of surveys applied to employers $(N=994)$, graduate students (2085), and academics $(N=1423)$ are included in Tables 2-4.

Thus we find that the ability to identify, formulate, and solve engineering problems occupies the first place for employers and graduates but appears in sixth place for academics. These results are consistent with the current university model of transmission of knowledge, with a deficit in development of competences related to practice abilities and attitudes. Another weakness, for example, is that the knowledge of a foreign language does not appear at the top of this ranking, despite this competence's being directly related to the European convergence goals (mobility).

With this ranking of competences and following the process schematized in Fig. 1, academic staff have made key decisions about the best way to modify, shape, and ultimately improve the academic program by explicitly linking their competences across several levels. Compe-

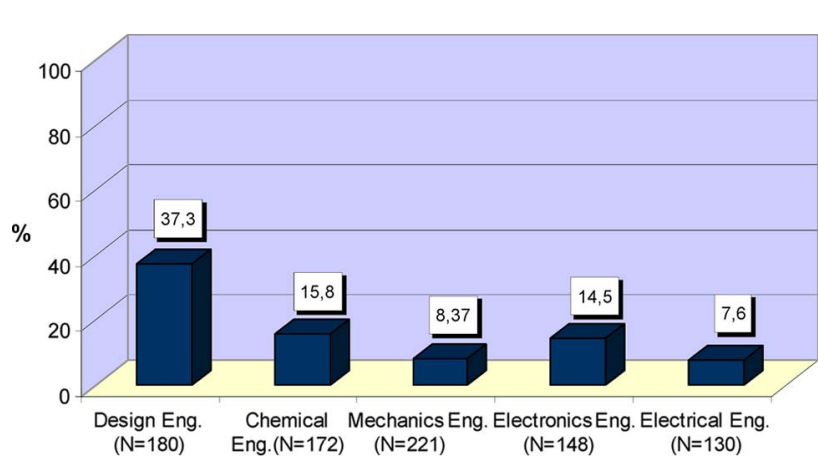

Fig. 4. Percentage of engineering students that claim to know ECTS.
Table 2 Ranking of Some Generic Competences ( $N=994$ Employers); Importance Level ( $4=$ Most Important to $1=$ Least Important)

\begin{tabular}{|l|c|}
\hline Competences & $X$ \\
\hline $\begin{array}{l}\text { Problem-solving (ability to identify, formulate, and solve } \\
\text { engineering problems) }\end{array}$ & 3,41 \\
\hline Decision-making & 3,40 \\
\hline Planning, coordinating and organizing & 3,39 \\
\hline Ability to apply knowledge in practice & 3,30 \\
\hline Team-work & 3,26 \\
\hline Motivation for quality and continuous improvement & 3,26 \\
\hline Capacity of analysis and synthesis & 3,22 \\
\hline
\end{tabular}

tences were embedded within individual courses and also aligned with the overall goals of academic programs.

We consider that competence-based educational initiatives should be embedded within a larger institutional planning process and that these linkages-aligning competences with course goals - are crucial for coherence in the curriculum [43], [44].

Many institutions in Europe claim to have a competence-based curriculum. However, in many cases, only superficial changes in the curriculum have taken place, and learning processes have not changed in practice. But as Adelman says, "What credits based on student workload do (at least if faculty reflect deeply as opposed to mechanically) is to spur changes to the shape and delivery of curriculum" [12, p. 61]. For this reason, we consider that it is necessary to redraw the curriculum with interdependent feedback loops, constructing a map of competences downwards from the top and upwards from the bottom after determining the core competences by deliberation and through a partaking process.

Table 3 Generic Competence Ranking. $N=2085$ Graduates: 630 Electrical Engineering (EI), 520 Electronics Engineering (E), 600 Mechancial Engineering (M), 250 Chemical Engineering (C), 85 Design engineering (D)

\begin{tabular}{|c|c|c|c|c|c|}
\hline \multirow{2}{*}{ Competences } & \multicolumn{5}{|c|}{$\mathrm{x}$} \\
\hline & $\begin{array}{c}\mathrm{El} \\
(630)\end{array}$ & \begin{tabular}{|c|}
$E$ \\
$(520)$
\end{tabular} & $\begin{array}{c}M \\
(600)\end{array}$ & $\begin{array}{c}\mathrm{C} \\
(250)\end{array}$ & $\begin{array}{c}\mathrm{D} \\
(85)\end{array}$ \\
\hline Problem-solving & 3,55 & 3,55 & 3,50 & 3,63 & 3,50 \\
\hline $\begin{array}{l}\text { Ability to apply knowledge in } \\
\text { practice }\end{array}$ & 3,67 & 3,48 & 3,48 & 3,67 & 3,48 \\
\hline Basic knowledge & 3,61 & 3,49 & 3,40 & 3,46 & 3,40 \\
\hline Innovation & 3,36 & 3,40 & 3,34 & 3,38 & 3,34 \\
\hline Inititative & 3,52 & 3,37 & 3,33 & 3,38 & 3,33 \\
\hline Team-work & 3,33 & 3,19 & 3,16 & 3,2 & 3,16 \\
\hline Decision-making & 3,36 & 3,24 & 3,14 & 3,25 & 3,14 \\
\hline Leadership & 3,21 & 2,96 & 2,98 & 2,96 & 2,98 \\
\hline
\end{tabular}


Table 4 Ranking of Some Generic Competences ( $N=1423$ Academics)

\begin{tabular}{|l|c|}
\hline Competences & $\mathrm{X}$ \\
\hline Ability to apply knowledge in practice & 3,47 \\
\hline Basic professional knowledge & 3,44 \\
\hline Ability to understand professional and ethical responsibility & 3,42 \\
\hline Ability to function on multidisciplinary teams & 3,41 \\
\hline Critical reasoning & 3,34 \\
\hline Problem solving & 3,26 \\
\hline
\end{tabular}

Table 5 First Approximation to "Core" Competences in Electronic Engineering Curriculum

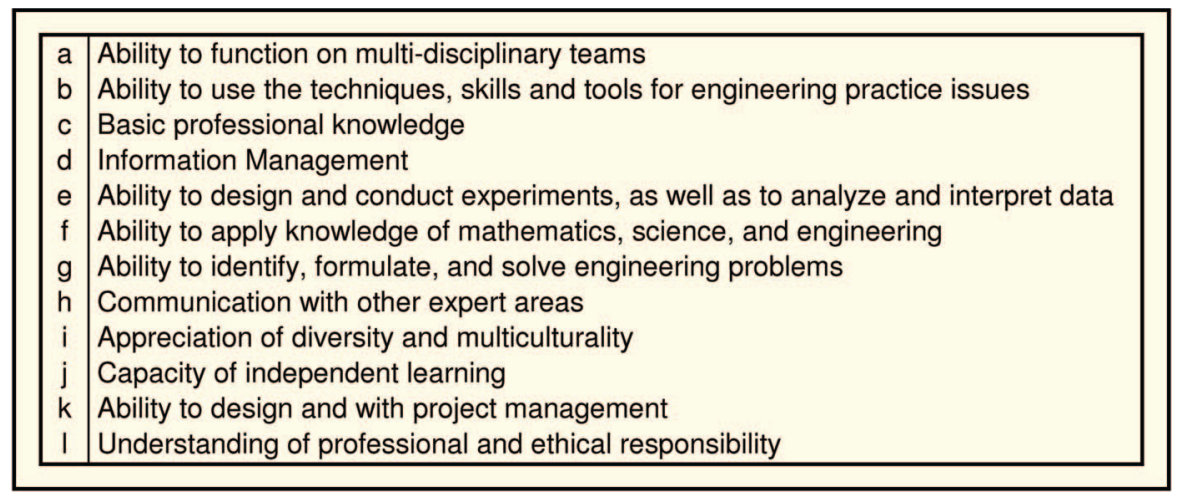

In Table 5 and Fig. 5, we show examples of the first approximation to "core" competences developed in electronic engineering.

We observe how instrumental competences prevail over interpersonal and systemic competences. Most universities in Spain are still centered in competences and cognitive outcomes related to knowledge acquisition, showing that the change of paradigm is hard to achieve.

The Spanish legal framework for the implementation of the main instruments included in the statements and communiqués of the ministers responsible for higher education in Bologna (1999), Prague (2001), and Berlin (2003) has been fulfilled. Rules concerning the use of the European credit system (2003), issuing the diploma supplement by universities (2003), and the validation and assessment of study programs and official degrees (2004) are already in force. The government has approved (January 2005) by royal decree the two basic regulations for the establishment of a new structure of higher education programs and has opened the process of renewal of the study programs in three levels: graduate, master's, and doctorate. This royal decree establishes the three Bologna cycles comparable in duration to those existing in other European countries and will lead to a reduction of the content of core curriculum, which will be based on learning outcomes and competences.
At present, we are working on a second stage of deepening and enriching the "core" map of competences (and including competences related to fluency in foreign languages). We are addressing the following questions.

1) Where in the curriculum and at what level do students learn and practice these competences? (competence itineraries).

2) What teaching strategies and assignments are given to students in order to help them develop these attributes?

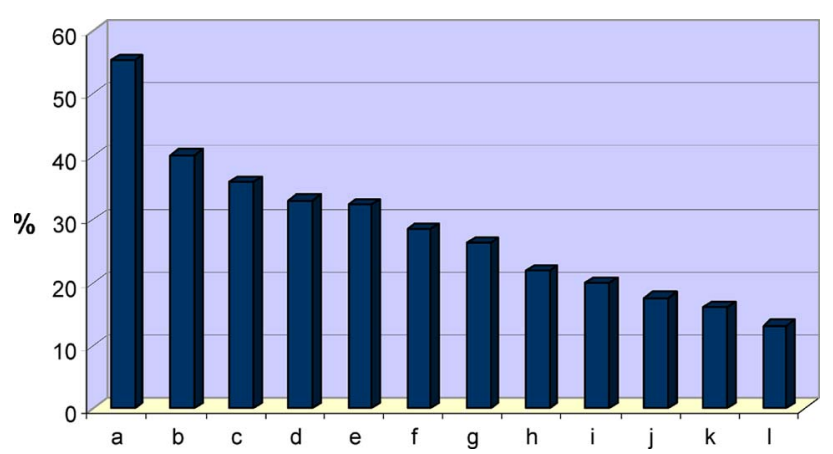

Fig. 5. Percentage of the "core" competences embedded into electronic engineering curriculum $(N=57)$. 
3) What assessments (methodologies, resources, and instruments) are to be selected to determine if students are mastering the competences?

4) How do we develop and improve indicators in order to guarantee the expected learning outcomes? (assessment and quality assurance)

\section{CONCLUSION AND COMMENTS}

Competence-based education-and, more specifically, competence-based learning - is the leading paradigm for innovation in knowledge societies. The concept of competence (and learning outcomes) is becoming the basis for the redesign of future curriculum proposals in Spain in the same way as in several European countries. Although the prevalent conceptual perspectives of competence-based learning in Europe are associated with constructivist theories of learning, there is confusion, debate, and increasing criticism concerning the concept of competence. At present, it is impossible to identify or impute a coherent theory or to reach a definition capable of accommodating and reconciling the different ways in which the term is used, and we can say that there is no theoretical framework for competence. Since reform is approaching, educators and trainers are in the early developing stages trying to explore the meaning and implications of competences and learning outcomes in practice.

Our experience has enabled us to establish a set of "strong principles" or key considerations in the decisionmaking process to define map competences. Attention must be paid to concerns about validity and reliability of competences, while institutions can glean meaningful information to improve their initiatives by asking and improving the participation of different stakeholders. Potential participants include the faculty, academics, grad- uates, students, and employers who hire the graduates. We consider that once faculty have identified and reviewed relevant and potential competences, they must determine the best strategy to obtain formal feedback from their constituencies. These formal strategies to identify the relevant competences are typically research-based and require a systematic analysis of results in order the information to be meaningful, useful, and valid. Participation, commitment, and critical reflection of the educative community are the mechanisms to construct a community of practice and to move competence development from "theory to practice."

A major challenge for teachers (and students) is to ensure that competences are both valid and reliable, with the ultimate aim being, in practice, that they are fully transportable throughout and outside the institution. But up to now, this standardization of terminology and semantics across European countries has been difficult to carry out.

It is not clear how problems related to transportability of competence assessment and credentials across states and institutions will be solved. There is a need to keep paying attention to transportability learning issues, as well as to associated experiences across academic programs and institutions by focusing on how reliability and validity of competences and their assessment are addressed. The success of the Bologna process in Spain depends upon an institutional change of academic culture, and improving the new paradigm of competence-based education will require some time.

\section{Acknowledgment}

The authors wish to thank all members of the School of Design Engineering in Valencia (ETSID) for their active participation in EHEA adaptation projects.

\section{REFERENCES}

[1] R. Kuhnke, "The training of tomorrow's engineers-Challenges of change," Global Eur. J. Eng. Educ., vol. 4, no. 3, pp. 257-261, 2000.

[2] Educating the Engineer of 2020. Washington, DC: National Academy of Engineering, 2005.

[3] C. Borri, "Reshaping the engineer for the 3rd millennium," Eur. J. Eng. Educ., vol. 28, no. 2, pp. 137-138, 2003.

[4] H. Heijke, C. Meng, and G. Ramaekers, "An investigation into the role of human capital competences and their pay-off," Research Memo., ROA, Maastricht, The Netherlands, 2002.

[5] U. Teichler and H. Schonburg, Eds., Comparative Perspectives on Higher Education and Graduate Employment and Work-Experiences From Twelve Countries. Amsterdam, The Netherlands: Kluwer, 2004.

[6] G. Brunello and S. Comi, "Education and earnings growth: Evidence from 11 European countries," Econ. Educ. Rev., vol. 23, pp. 75-83, 2004.

[7] A. Garcia-Aracil, J. Ginés Mora, and L. E. Vila, "The rewards of human capital competences for young european higher education graduates," Tert. Educ. Manage., vol. 10, no. 4, pp. 287-305, 2004.

[8] H. Biemans, L. Nieuwenhuis, R. Poell, M. Mulder, and R. Wesselink, "Competence-based VET in the Netherlands: Background and pitfalls," J. Voc. Educ. Train., vol. 56, no. 4, pp. 523-538, 2004.

[9] A. Gonczi, "Competency-based learning: A dubious past-An assured future?" in Understanding Learning at Work, D. Boud and J. Garrick, Eds. London, U.K.: Routledge, 1999, pp. 180-197.

[10] W. Westera, "Competences in education: A confusion of tongues," J. Curric. Studies, vol. 33, no. 1, pp. 75-88, 2001.

[11] J. González and R. Wagenaar, Eds., Tuning Educational Structures in Europe, University of Deusto and Groningen, Deusto, 2003. [Online]. Available: http://tuning.unideusto. org/tuningeu/

[12] C. Adelman, "The Bologna Club: Higher education can learn from a decade of European reconstruction," Institute for Higher Education Policy, Washington, DC [Online]. Available: http://www.ihep.org/ Research/GlobalPerformance.cfm
[13] A. Arguelles and A. Gonczi, Eds., Competency Based Education and Training: A World Perspective. Balderas, México: Editorial Limusa S.A., 2000.

[14] D. S. Rychen and L. H. Salganik, Eds., Defining and Selecting Key Competencies. Theoretical and Conceptual Foundations. Göttingen, Germany: Hogrefe \& Huber, 2001.

[15] A. Stoof, R. L. Martens, J. J. G. Van Merriënboer, and T. J. Bastiaens, "The boundary approach of competence: A constructivist aid for understanding and using the concept of competence," Human Res. Develop. Rev., vol. 1, pp. 345-365, 2002.

[16] R. Wesselink, H. J. A. Biemans, E. R. Van den Elsen, and M. Mulder, "Conceptual framework for competence-based VET in the Netherlands," in Proc. ECER 2005, Dublin, Ireland, 2005.

[17] L. M. Sánchez-Ruiz, M. Edwards, and E. Ballester-Sarrias, "Competence learning challenges in engineering education in Spain: From theory to practice," in Proc. 9th Int. Conf. Eng. Educ., Puerto Rico, Jul. 23-28, 2006.

[18] F. E. Weinert, "Concept of competence: A conceptual definition," in Defining and Selecting Key Competencies, D. S. Rychen and 
L. H. Salganik, Eds. Seattle, WA: Hogrefe \& Huber, 2001.

[19] M. Armstrong, "Demystifying competence," Human Res., pp. 49-50, Nov.-Dec. 1995.

[20] D. R. Moore, M. Cheng, and A. R. J. Dainty, "Competence, competency and competencies: Performance assessment in organizations," Work Study, vol. 51, pp. 314-319, 2002.

[21] J. R. Spencer, D. McClelland, and S. M. Spencer, Competency. Assessment Methods, History and State of the Art. London, U.K.: Hay/McBer Research, 1994.

[22] P. Descy and M. Tessaring, Training and Learning for Competence. Thessaloniki, Greece: Cedefop, 2001.

[23] P. McLagan, "Competencies. The next generation," Train. Develop., pp. 40-47, May 1997.

[24] G. Grant et al., On Competence: A Critical Analysis of Competence-Based Reforms in Higher Education. San Francisco, CA: Jossey-Bass, 1979.

[25] L. Vucht Tijssen van and E. De Weert, "From erudition to academic competence," Revista Española de Pedagogía, vol. 230, pp. 123-146, 2005.

[26] M. Eraut, Developing Professional Knowledge and Competence. London, U.K.: Falmer, 1994.

[27] R. L. Cross and S. B. Israelit, Strategic Learning in a Knowledge Economy. Individual, Collective, and Organizational Learning Process. London, U.K.: Butterworth-Heinemann, 2000.

[28] W. M. Sullivan, Work and Integrity: The Crisis and Promise of Professionalist in America. San Francisco, CA: Jossey-Bass, 2004.
[29] S. B. Parry, "Just what is a competency? (and why should you care?)," Training, pp. 58-64, Jun. 1998.

[30] J. Winterton, F. Delamare-Le Deist, and E. Stringfellow, "Typology of knowledge, skills and competencies: Clarification of the concept and prototype," Centre for European Research on Employment and Human Resources, Groupe ESC, Toulouse, France, Res. Rep. elaborated on behalf of Cedefop/ Thessaloniki, 2005.

[31] IEEE P1484.20 Competency Definitions Study Group, IEEE Learning Technology Standards Committee, 2000. [Online]. Available: http:// ltsc.ieee.org/wg20/index.html

[32] J. Earnest, "ABET engineering technology criteria and competency based engineering education," Presented at the ASEE/IEEE Frontiers Educ. Conf., Indianapolis, IN Oct. 19-22, 2005.

[33] N. Norris, "The trouble with competence," Cambridge J. Educ., vol. 21, no. 3 , pp. 1-11, 1991.

[34] J. Boon and M. van der Klink, "Competencies: The triumph of a fuzzy concept," in Proc. Acad. Human Res. Develop. Annu. Conf., Honolulu, HI, Feb. 27-Mar. 3, 2002, vol. 1, pp. 327-334.

[35] B. Mansfield, "Competence in transition," J. Eur. Ind. Train., vol. 28 , no. $2 / 3 / 4$, pp. 296-309, 2004.

[36] F. Lasnier, Réussir la Formation par Compétences. Montreal, PQ, Canada: Guérin, 2000.

[37] "Marco sobre la integración del sistema universitario español," 2003. [Online]. Available: http://wwwn.mec.es

[38] P. Idowu, "In search of a perfect power engineering program," IEEE Trans. Educ., vol. 47, no. 3, pp. 410-414, 2004.
[39] M. Edwards, E. Ballester-Sarrias, P. Fuentes-Durá, and V. Donderis-Quiles, "Perceptions et avis du professorat espagnol sur le processus de convergence," in Proc. 22ème Congrès de l'Assoc. Int. Pédagogie Univ., Genève, Switzerland, 2005.

[40] M. Edwards, V. Donderis-Quiles,

L. M. Sánchez-Ruiz, and E. Ballester-Sarrias, "Approach to the european higher education area in the school of design engineering," in Proc. 9th Int. Conf. Eng. Educ., Puerto Rico, Jul. 23-28, 2006

[41] "Engineering criteria 2000 3rd Edition: Criteria for accrediting programs in engineering in the United States," Accreditation Board for Engineering and Technology, Baltimore, MD.

[42] M. Besterfield-Sacre, L. J. Shuman, H. Wolfe, C. J. Atman, J. McGourty, R. L. Miller, B. M. Olds, and G. Rogers, "Defining the outcomes: A framework for EC 2000," IEEE Trans. Eng. Educ., vol. 43, no. 2, pp. 100-110, 2000

[43] M. Spector and T. M. Anderson, Integrated and Holistic Perspectives on Learning, Instruction and Technology: Understanding Complexity. Norwell, MD: Kluwer Academic, 2000.

[44] H. P. A. Boshuizen, "Does practice make perfect? A slow and discontinuous process," in Professional Learning: Gaps and Transitions on the Way From Novice to Expert, H. P. A. Boshuizen, R. Bromme, and H. Gruber, Eds. Dordrecht, The Netherlands: Kluwer Academic, 2004.

\section{ABOUT THE AUTHORS}

Mónica Edwards received the bachelor's degree in science education (1981) and her Master degree in Electronic Engineering from the National Technological University of Cordoba, Argentina, in 1981 and 1990, respectively, and the Ph.D. degree in physics from the University of Valencia, Spain, in 2003. She received postgraduate diplomas in knowledge management and engineering and innovation projects in 2004 and 2006, respectively.

She is a Researcher with the Institute of Inno-

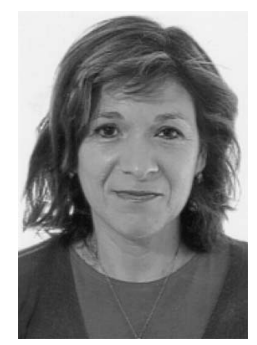
vation and Knowledge Management (INGENIO), a joint Institute of the Spanish Council for Scientific Research and the Polytechnic University of Valencia. From 1991 to 1997, she was a Lecturer with the Chemical Department, National University of Cordoba, and Engineer responsible for managing the Infrared and Nuclear Magnetic Resonance Spectroscopy Laboratory. She has been in Valencia since 1997, where she is involved in training and consultancy in strategic planning, educative innovation, and organizational culture change. She is the author or coauthor of 90 papers in scientific journals and conference proceedings.

Luis Manuel Sánchez-Ruiz received the Ph.D. degree from the Universidad de Valencia, Spain.

He has been with the Universidad Politécnica de Valencia, Spain, since 1980, where he became a full Professor of mathematics in 2000. He was a Visiting Professor at the University of Florida, Gainesville, on several occasions during 19921999. His lecturing has been addressed mainly to electronic engineering and aeronautic engineering students. His current research interests include functional analysis from theoretical and applied points of view. He has published more than 120 papers in scientific journals and conference proceedings and more than ten textbooks on mathematics for engineers. He is coauthor of a research monograph and former Academic Coordinator of Mediterranean University of Science and Technology. He is currently Director of the UPV Programs Office with USA and Asia and a member of the Editorial Board of Scientiae Mathematicae Japonicae. He has been responsible for several research projects granted by the Spanish Ministry of Education and a member of several International Steering Committees on Engineering Education (becoming General Chair of ICEE2003 Valencia) as well as several WSEAS international conferences.

Carlos Sánchez-Díaz was born in Spain in 1967. He received the master's degree in electronic engineering from the Universidad de Valencia, Spain, in 1998 and the Ph.D. degree in power electronics from the Universidad Politécnica de Valencia, Spain, in 2004.

$\mathrm{He}$ is a Lecturer in the Department of Electronic Engineering, Universidad Politécnica de Valencia. Since 2004, he has been a Committee Coordinator in the development of the degree in industrial

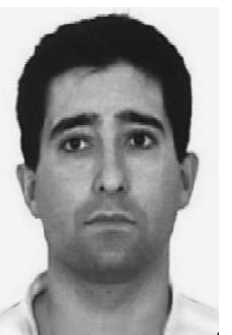
electronics and automatic engineering in the Bologna process framework. His postdoctoral research was conducted at the Institute for Energy Engineering in the same university. His present research activities are in the area of renewable energy, integration of hydrogen production, storage, and electrical energy generation systems. 